\title{
The Experimental Research of Drying Kinetics of Nagpur Orange Fruit (Citrus Sinesis- L) by Hot Air Electrical Dryer
}

\author{
Prashant M.Rewatkar, M.Basvaraj, V.B.Huddar
}

\begin{abstract}
The study is aimed experimentally and compared with the theoretical results of drying kinetics of Nagpur orange fruit dried in a hot air electrical dryer. Orange fruit is highly perishable and needs to be consumed or processed immediately after harvest. Drying or dehydration is one of the most practical methods of preserving food products. Therefore, thin layer drying characteristics of falling rate of Nagpur orange are determined experimentally under different conditions of drying air temperatures, relative humidity and air velocities for different moisture contents. Thin layer models like Wang and Singh, Page and Henderson have been compared with Experimental results. The knowledge of drying kinetics helps for identification of exact drying time and air flow velocity for different moisture content. Here drying operation is carried out at a velocity of $1 \mathrm{~m} / \mathrm{sec}$ and $1.25 \mathrm{~m} / \mathrm{sec}$ for different temperature of $55^{\circ} \mathrm{C}, 65^{\circ} \mathrm{C}$ and $75^{\circ} \mathrm{C}$. This analysis reveals that drying temperature has a more significant effect on moisture removal while velocity has the least effect. Drying rate is found to increase with the increase in drying temperature and reduce with drying time. Experimental data is statistically correlated by plotting the drying characteristics curve. The analysis reveals that Wang and Singh's model is a better model to explain the drying behavior of Nagpur Orange fruit $(\mathrm{R} 2=0.9888)$.
\end{abstract}

Key words: Nagpur orange fruit, Moisture content, Temperature and Velocity.

\section{INTRODUCTION}

Orange city is named to Nagpur as a "The Orange City" as it produces highest production throughout India. Orange crops in Nagpur Dist, occupy 15,205 hacker with a production of $1,40,613$ tons of Oranges per year [1,2]. Orange fruit have limited shelf life because of high moisture content; therefore, it is necessary to utilize oranges for making different products to increase its accessibility for a long period of time. This would definitely help to control the price during off seasons. But actually, when we have seen in Nagpur, Santra Market tones of orange fruits were wasted per day due to a huge production at a particular period of time because this is seasons based growth fruit and it has to be used very judiciary. This wastage shall be minimized by means of having proper storage facility, processing unit and processing units. There is a need to preserve Nagpur Orange fruit for longer period by adopting these methods.

Drying is one of the important and oldest methods in the preservation of agricultural products. Drying is a complex

Revised Manuscript Received on April 12, 2019.

Prashant M.Rewatkar, Bearys Institute of Technology, Mangaluru, India. (revatkar.prashant@gmail.com)

Dr. M.Basvaraj, Bearys Institute of Technology, Mangaluru, India (vbhuddar2017@gmail.com)

Dr. V.B.Huddar, Bearys Institute of Technology, Mangaluru, India. (vbhuddar2017@gmail.com) process involving simultaneous heat and mass transfer under transient conditions which include changes in the material during drying.

The main objective of drying is to remove water at an optimum level at which deterioration reactions at the microbial spoilage are greatly reduced. Drying kinetics is generally assessing experimentally by measuring drying sample weight as a function of time [3]. In modern technology for designing air drying equipment mathematical description of food moisture movement requires knowledge of drying kinetics'[4]. A mathematical model of the drying process is used for designing and improvement of existing drying system and controlling the drying process [5]. Drying curves described completely drying process at different moisture ratio. The models like Newton Wang and Singh, Page and Henderson and Pabis are mostly used for food and biological materials for comparing the drying characteristics of food products. The moisture diffusion is explained by the following equation. [6]

$$
\mathrm{MR}=\frac{M_{d i}-M_{d e}}{M_{d o}-M_{d e}}
$$

Where, $M R=$ Moisture Ratio

$M_{d i}=$ Moisture content of the sample at any time $t i$

$M_{d e}=$ Moisture content at equilibrium,

$M_{d o}=$ Original or Initial Moisture Content

Drying Rate (RD) on mass basis (any time) is given by: $R D d i=\frac{m i-1-m i}{m d \times(t i-1-t i)}$

Where: $m i=$ Initial Mass (gms)

$$
m d=\text { Final mass }(\mathrm{gms})
$$$$
t i=\text { Time }(\mathrm{min})
$$

The basic objective of this experimental study is to investigate drying kinetics of Nagpur orange fruits (Citrus sinesis-L) as a function of air temperature and velocity on drying behavior.

\section{MATERIAL AND METHODOLOGY}

Figure 1 shows the experimental setup of hot air Electrical dryer developed by an author in collaboration with Mahatma Gandhi Institute for rural industrialization (MGIRI), Wardha- 442001, Maharashtra. This dryer is suitable for the desired drying conditions over a wide range 


\section{THE EXPERIMENTAL RESEARCH OF DRYING KINETICS OF NAGPUR ORANGE FRUIT (CITRUS SINESIS- L) BY HOT AIR ELECTRICAL DRYER}

of parameters. This dryer consists of drying chamber $(920 \times 770 \times 460 \mathrm{~mm})$ full insulated with muff; four aluminum trays $(670 \mathrm{~mm} \times 400 \mathrm{~mm})$ placed one over other, two centrifugal blowers with air filter and digital temperature indicator control panel with relay indicator. Forced convection is implemented which increases the efficiency of the dryer and also use the recirculation technique is adopted. The patent was filed by MGIRI Application No. 201621006240, date of filling 15/09/2015.
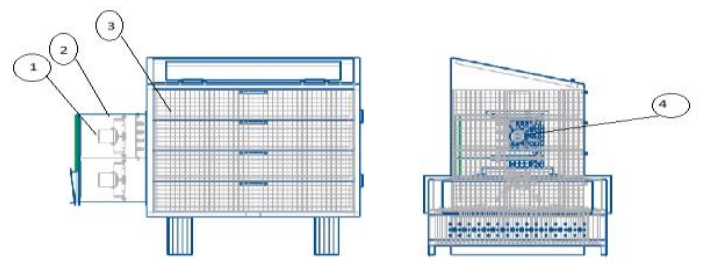

Figure 01: Experimental set-up
1) Centrifugal blower
2) Control panel
3) Drying tray
4) Air ducting
5) Drying chamber

\section{METHODOLOGY}

Freshly harvested Nagpur orange fruit which are in uniform size and colour were selected from Nagpur Santra local market (Karanja Region Area, Vidarbha India). After peeling the outer surface, the inner fruit is washed in clean water. A weight of each sample was measured by digital weight balance. The drying chamber is equilibrated for 20 minutes with room temperature before placing the trays in the dryer chamber. For drying process, it was run for the desired temperature level of $55^{\circ} \mathrm{C}, 65^{\circ} \mathrm{C}$ and $75^{\circ} \mathrm{C}$ of drying air temperature. During the drying, the process tray was taken out at different time intervals to measure weight loss for drying curves. All drying experiment carried in triplicate.

\section{RESULTS AND DISCUSSIONS:}

\section{A. Effect of temperature on drying characteristics}

Figure $2 \& 3$ shows the effect of different drying temperature $55^{\circ} \mathrm{C}, 65{ }^{\circ} \mathrm{C}$, and $75{ }^{\circ} \mathrm{C}$ on the moisture content of Nagpur orange fruit with drying time at air velocity $1 \mathrm{~m} / \mathrm{s}$ and $1.5 \mathrm{~m} / \mathrm{s}$. It is seen that moisture content (DB) decreases with an increase in drying time for above said temperatures. This occurs due to the formation of shrinkage as moisture evaporates. The rate of shrinkage formation will be faster as compared to moisture removal. It is observed that the shrinkage in the initial period is more and subsequently it remains constant indicating the marginal change in the mass of the sample. This is in good agreement with the earlier researcher which have been reported in the drying of various fruits and vegetables. [7-8]. Heat and mass transfer coefficients between drying air increases with an increase in velocity of drying air which results in a decrease in drying time. From figures, it is observed that velocity has a very small effect on the drying behavior of the sample. [9]
Effect of Temp on Moisture Content (wb) V=1.0 m/sec ,124.00 gm

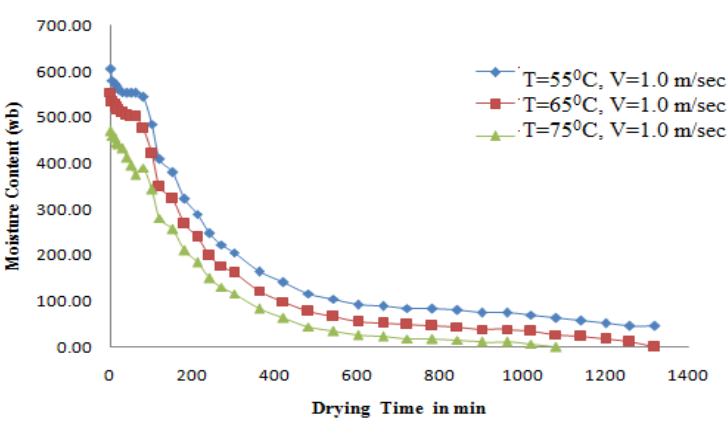

Figure 2: Variation of moisture content with drying time at different air temperatures and velocity of $1.0 \mathrm{~m} / \mathrm{sec}$ for a mass of 124.0 grams

\section{B. Effect of Temperature on Moisture Ratio}

Fig. $4 \& 5$ indicates the variation of moisture ratio with drying time of Nagpur orange fruits at temperature $55^{\circ} \mathrm{C}$, $65^{\circ} \mathrm{C}$ and $75^{\circ} \mathrm{C}$ at a velocity of $1.25 \mathrm{~m} / \mathrm{s}$ experimentally

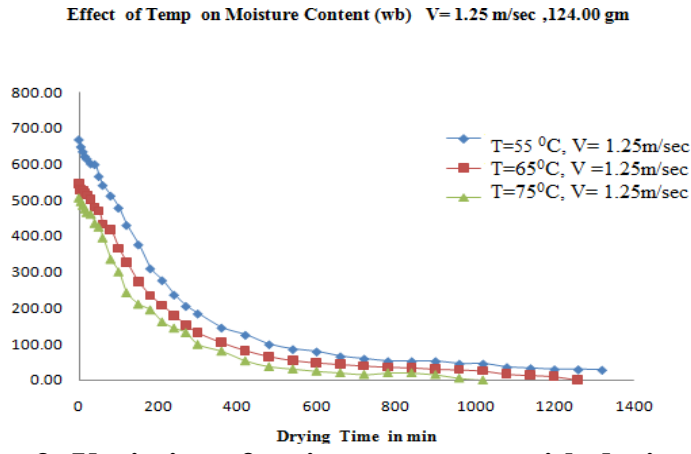

Figure 3: Variation of moisture content with drying time at different air temperatures and velocity of $1.25 \mathrm{~m} / \mathrm{sec}$ for a mass of 124.0 gram

\section{Effect of Temperature on Moisture Ratio}

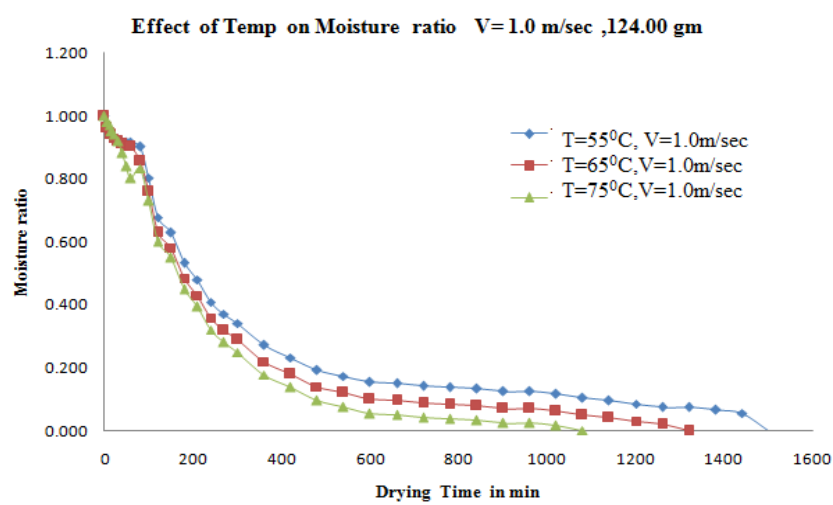

Figure 4: Variation of moisture ratio with drying time at different air temperatures and velocity of $1.0 \mathrm{~m} / \mathrm{sec}$ for a mass of 124 gram

Fig. $4 \& 5$ indicates the variation of moisture ratio with drying time of Nagpur orange fruits at temperature $55^{\circ} \mathrm{C}$, $65^{\circ} \mathrm{C}$ and $75^{\circ} \mathrm{C}$ at a velocity of $1.25 \mathrm{~m} / \mathrm{s}$ experimentally. It 
is observed that removal of moisture content at the beginning of the drying process is fast. Drying rate slows down as drying time increases. Moisture ratio decreases with drying time exponentially. Due to the decrease in relative humidity of air drying temperature increases with drying rate. Temperature increases from $55^{\circ} \mathrm{C}$ to $75^{\circ} \mathrm{C}$ which decreases in drying time from $1500 \mathrm{~min}$ to $1100 \mathrm{~min}$ at velocity $1 \mathrm{~m} / \mathrm{s}$.

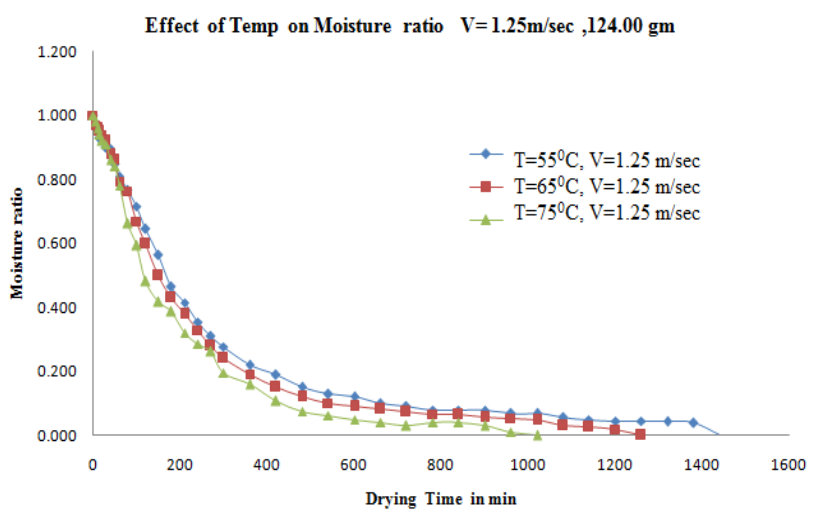

Figure 5: Variation of moisture ratio with drying time at different air temperatures and velocity of $1.25 \mathrm{~m} / \mathrm{sec}$ for a mass of 124 gram.

The Wang and Singh model has the highest value of Regression analysis $\mathrm{R} 2=0.9711$ at a temperature of $55^{\circ} \mathrm{C}$ at velocity $1 \mathrm{~m} / \mathrm{s}$ having predicted equation $3 \mathrm{E}-06 \mathrm{t} 2$ $0.012 \mathrm{t}+1$.

\section{Effect of Temperature on Drying Rate}

Fig.6 \& 7 shows the variation of drying rate with drying time for Nagpur orange fruit at different temperature of $55^{\circ} \mathrm{C}, 65{ }^{\circ} \mathrm{C}$, and $75{ }^{\circ} \mathrm{C}$ at a velocity of $1.0 \mathrm{~m} / \mathrm{s}$ drying rate affected by different temperatures and observed in a falling rate period. The drying rate decreases continuously because of quick moisture removal from the surface of the orange fruit sample. At the starting moisture present in orange is very high the drying rate is also high. Drying rate when approaches to equilibrium moisture content it shows a slow drying rate.

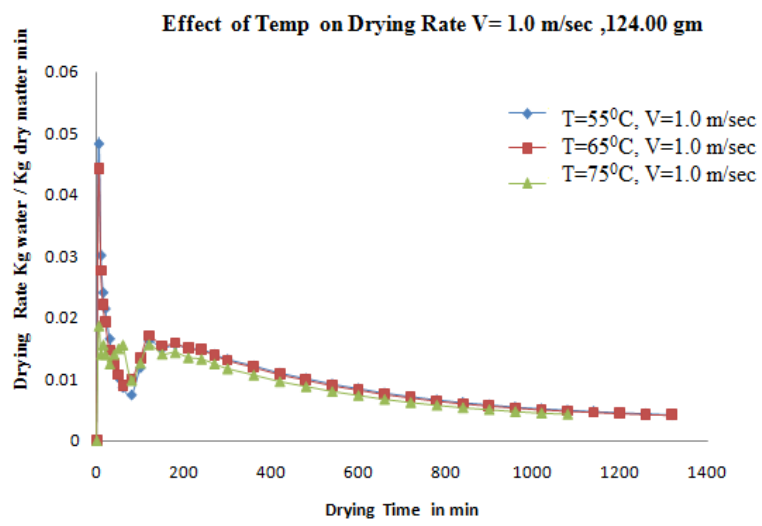

Fig. 6. Variation of Drying Rate with drying time at different air temperatures and velocity of $1.0 \mathrm{~m} / \mathrm{sec}$ in the falling rate period for a mass of 124 gram

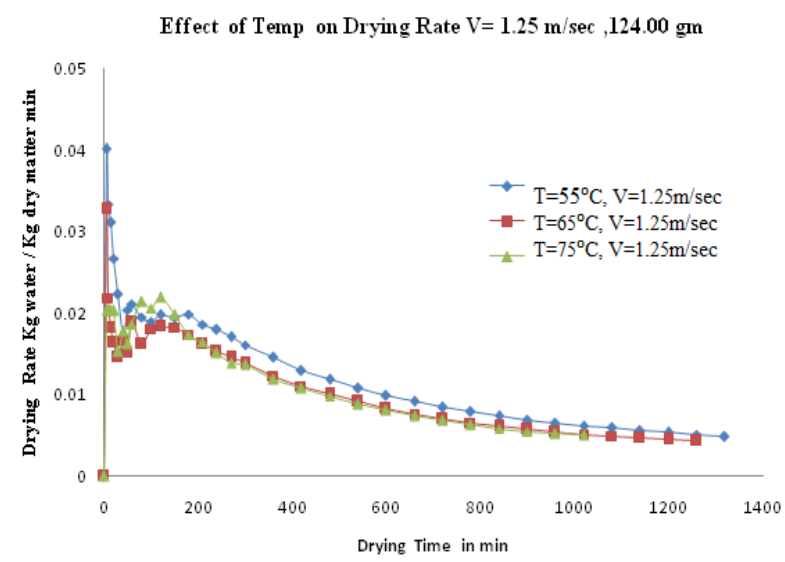

Figure 7: Variation of drying rate with drying time at different air temperatures and velocity of $1.25 \mathrm{~m} / \mathrm{sec}$ in the falling rate period for a mass of 124 gram.

\section{CONCLUSION}

Drying kinetics of Nagpur orange fruit was studied and analyze as a function of drying time and 02 velocities for temperatures $55^{\circ} \mathrm{C}, 65{ }^{\circ} \mathrm{C}$, and $75{ }^{\circ} \mathrm{C}$. The effect of air temperature on drying characteristics was more significant as compare to air velocity. Drying rate is higher at higher temperature and consequently moisture ratio decrease faster. It is due to increase of air heat supply to the sample and faster migration of moisture was found in the sample. The whole drying process occurs during falling rate period, it is proved that effect of drying temperature and drying time is more significant then air velocity. It was found that drying time is more for more temperature at $55^{\circ} \mathrm{C}$ and small at $75^{\circ} \mathrm{C}$ from the statistical analysis it is concluded that Wang and Sing model $\left(\mathrm{R}^{2}=0.9888\right)$ is the most suitable model for drying behavior of Nagpur orange fruit ( Citrus Sinesis- L).

\section{REFERENCES:}

1. Ropan Bante,Sarju Pallewar, "Economics of Orange production in Nagpur district of Maharashtra", IRJAC, vol.6 (2105)

2. E.Kuruzowa,A,A. El-Aouar, M.R. Simoes F. E. X Murr. "Determination of Thermal properties of (Carica papaya L) as a function of temperature" $4^{\text {th }}$ Mercosur Congress on Process Engineering.

3. Mujumdar, A. S., Hand Book of industrial drying, (Marcel Dekker, New York, 1987.) 1- 40.

4. Hernandez, J.A., Pavon, G., Garcia, M. A., Analytical solution of mass transfer equation considering shrinkage for modeling food drying kinetics, Journal of food engineering, 45, 2000, 1 - 10

5. Menges, H.O., Ertekin. C., Modeling of air drying of Hacihalilioglu- type apricots, J Sci Food Agric., 86, 2006, 279-291.

6. Crank. J, The Mathematics of Diffusion (UK Oxford University press, London, 1975).

7. Madamba, P.S., Thin Layer drying models for osmotically pre-dried young coconut, Drying Technology, 21, 2003, $1759-1780$. 
8. Akpinar, E. K., Bicer, Y., Midilli, A, Modeling and experimental Study on drying of apple slices in a convective cyclone dryer, J Food Process Engg., 26, 2003, 515 - 541.

9. Shiv kumar modi ,Basavaraj M, “ Exprimental sudy of drying kinetics of Guava fruit (Psidium Guajava L) By Thin Layer Drying" IOSR Journal of Environmental Science, Toxicology and Food Technology Volume 9, Issue 1 Ver. I (Jan. 2015), PP 74-80 